\title{
Bone Health TeleECHO for Orthopedists and Rheumatologists
}

\author{
*E Michael Lewiecki \\ New Mexico Clinical Research \& Osteoporosis Center, USA \\ Submission: June 27, 2017; Published: June 29, 2017 \\ *Corresponding author: E Michael Lewiecki, New Mexico Clinical Research \& Osteoporosis Center, 300 Oak St. NE, New Mexico 87106, \\ Albuquerque, USA, Tel: 505-855-5525; Fax 505-884-4006; Email :mlewiecki@gmail.com
}

Keywords: Project ECHO; Osteoporosis; Telehealth; Telemedicine; Videoconferencing

\section{Mini Review}

Osteoporosis is a skeletal disease characterized by compromised bone strength predisposing to an increased risk of fracture [1]. It is an important public health concern, affecting about 200 people worldwide [2] and causing approximately 9.0 million fractures each year [3]. While physicians of almost any specialty may have patients with osteoporosis and other chronic skeletal diseases, orthopedists and rheumatologists are particularly well positioned to care for these patients or direct them to someone who can. Orthopedists treat patients with fractures and perform arthroplasties, the outcomes of which may be influenced by the management of osteoporosis. Rheumatologists see patients with chronic inflammatory diseases, which are risk factors for osteoporosis, and treat with medications, especially glucocorticoids, that may have devastating skeletal effects. Unfortunately, osteoporosis diagnosis and treatment rates are generally poor and getting worse, with recent evidence that hip fracture rates in recent years are higher than expected [4]. After a hip fracture, most patients are not treated to reduce the risk of future fractures [5].

Better education of healthcare professionals is one of several approaches that have been suggested [6] to address the crisis in osteoporosis care [7]. However, there are many competing priorities in clinical practice, with physicians having limited available time to devote to medical education and uncertainty of effectiveness of traditional learning methods (e.g., scientific journals, medical congresses, local lectures) to change practice patterns. To overcome these challenges, an innovative method of sharing knowledge through case-based learning using videoconferencing technology has been developed. Bone Health TeleECHO® (extension of community health outcomes) was established through collaboration of Project ECHO at the University of New Mexico Health Sciences Center (UNM HSC) and the Osteoporosis Foundation of New Mexico, in Albuquerque, New Mexico, USA.

The ECHO modelTM [8] originated with remote learning to improve the care of chronic hepatitis C in rural New Mexico. In a proof-of-concept study, this was shown to improve outcomes to a level that was similar to a university specialty clinic [9]. The ECHO model has since been adapted in many world regions for the care of many diseases, including osteoporosis [10]. The potential reach of teleECHO to transform medical education has been recognized by the US federal government through the "ECHO Act" [11], signed by President Obama in December 2016. This is a bill that requires studies and reports examining the use of, and opportunities to use, technology-enabled collaborative learning and capacity building models to improve programs of the US Department of Health and Human Services (HSS). It mandates that HHS provide a report to Congress within two years.

Bone Health TeleECHO, launched in October 2015, is a weekly online videoconference that links experts and learners with a focus on presentations and discussions of real but deidentified patients with skeletal disorders. A typical online clinic includes 35-40 participants located throughout the US and in some other countries. All participants are able to ask questions, make comments, and engage in discussions. This is much the same as learning during postgraduate medical training, except that it is done remotely instead of in person. There is no cost for participation. Continuing medical education credits are offered at no cost. Learning takes place without the need for travel, with minimal disruption of office routines. This may mitigate professional isolation and burnout that is common in rural communities. Through regular participation, learners can achieve an advanced level of knowledge, allowing them 
eventually provide specialty level care for osteoporosis for their own patients and patients of other healthcare providers in the community.

Patients receive better care, closer to home, with greater convenience and lower cost than referral to a specialty center. The ECHO model has a force multiplication effect in that it can improve the care of many patients, not just a few. The effect is enhanced even more when there are many teleECHO clinics in different states and countries. This has already begun with Bone Health TeleECHO, with a second teleECHO "hub" in Michigan and others in development.

Orthopedists and rheumatologists, as well as advanced practice providers working with them, can benefit from participation in teleECHO. Regardless of the baseline level of knowledge, learning through case discussions in a collegial setting, with no time away from office and family, is professionally gratifying and provides benefits at many levels. For orthopedists and rheumatologists who are experts and enjoy sharing their knowledge by teaching, Bone Health TeleECHO provides a platform for doing so. The ECHO Institute has been established at UNM HSC to provide support, at no cost, for the development teleECHO clinics worldwide.

\section{Conflict of Interest}

Research grant support from Amgen; consulting fees from Amgen, Radius, Shire, Alexion, and Ultragenyx; speaking fees from Radius, Shire, and Alexion; and board membership with the National Osteoporosis Foundation, International Society for Clinical Densitometry, and the Osteoporosis Foundation of New Mexico.

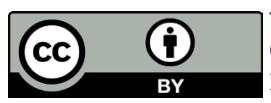

This work is licensed under Creative Commons Attribution 4.0 License DOI: $10.19080 /$ OROAJ.2017.07.555716

\section{References}

1. Klibanski A, Adams-Campbell L, Bassford T, Blair SN, Boden SD, et al. (2001) Osteoporosis prevention, diagnosis, and therapy. JAMA 285(6): 785-795.

2. Kanis JA (2007) On behalf of the World Health Organization Scientific Group. Assessment of osteoporosis at the primary health-care level. Technical Report: World Health Organization Collaborating Centre for Metabolic Bone Diseases, University of Sheffield, University of Sheffield, UK.

3. Johnell O, Kanis JA (2006) An estimate of the worldwide prevalence and disability associated with osteoporotic fractures. Osteoporos Int 17(12): 1726-1733.

4. Lewiecki EM, Adler RA, Curtis JR, Gagel R, Saag KG, et al. (2016) Hip fractures and declining DXA testing: at a breaking point? J Bone Miner Res 31(Suppl): S26.

5. Solomon DH, Johnston SS, Boytsov NN, McMorrow D, Lane JM, et al. (2014) Osteoporosis medication use after hip fracture in U.S. patients between 2002 and 2011. J Bone Miner Res 29(9): 1929-1937.

6. American Society for Bone and Mineral Research (2016) Call to Action to Address the Crisis in the Treatment of Osteoporosis, Washington DC, USA.

7. Khosla S, Shane E (2016) A Crisis in the Treatment of Osteoporosis. J Bone Miner Res 31(8): 1485-1487.

8. University of New Mexico School of Medicine (2017) Project ECHO. Project ECHO: A Revolution in Medical Education and Care Delivery, New Mexico, USA.

9. Arora S, Thornton K, Murata G, Deming P, Kalishman S, et al. Outcomes of treatment for hepatitis $\mathrm{C}$ virus infection by primary care providers. N Engl J Med 364(23): 2199-2207.

10. Lewiecki EM, Boyle JF, Arora S, Bouchonville MF, Chafey DH (2017) Telementoring: a novel approach to reducing the osteoporosis treatment gap. Osteoporos Int 28(1): 407-411.

11. S. 2873 (114 $\left.{ }^{\text {th }}\right)$ : ECHO Act. (2004) Govt Track. USA.

\section{Your next submission with Juniper Publishers} will reach you the below assets

- Quality Editorial service

- Swift Peer Review

- Reprints availability

- E-prints Service

- Manuscript Podcast for convenient understanding

- Global attainment for your research

- Manuscript accessibility in different formats

( Pdf, E-pub, Full Text, Audio)

- Unceasing customer service

Track the below URL for one-step submission https://juniperpublishers.com/online-submission.php 